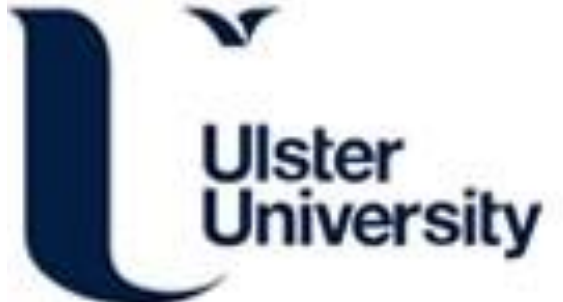

\section{Predictive Learning Analytics and the Creation of Emotionally Adaptive Learning Environments in Higher Education Institutions: A Study of Students' Affect Responses}

\begin{abstract}
Joseph-Richard, P., Jaffrey, A., \& Uhomoibhi, J. (2021). Predictive Learning Analytics and the Creation of Emotionally Adaptive Learning Environments in Higher Education Institutions: A Study of Students' Affect Responses. International Journal of Information and Learning Technology, 38(2), 243-257. https://doi.org/10.1108/IJILT-05-2020-0077
\end{abstract}

Link to publication record in Ulster University Research Portal

Published in:

International Journal of Information and Learning Technology

Publication Status:

Published online: 10/03/2021

DOI:

10.1108/IJILT-05-2020-0077

Document Version

Author Accepted version

\section{General rights}

Copyright for the publications made accessible via Ulster University's Research Portal is retained by the author(s) and / or other copyright owners and it is a condition of accessing these publications that users recognise and abide by the legal requirements associated with these rights.

\section{Take down policy}

The Research Portal is Ulster University's institutional repository that provides access to Ulster's research outputs. Every effort has been made to ensure that content in the Research Portal does not infringe any person's rights, or applicable UK laws. If you discover content in the Research Portal that you believe breaches copyright or violates any law, please contact pure-support@ulster.ac.uk. 


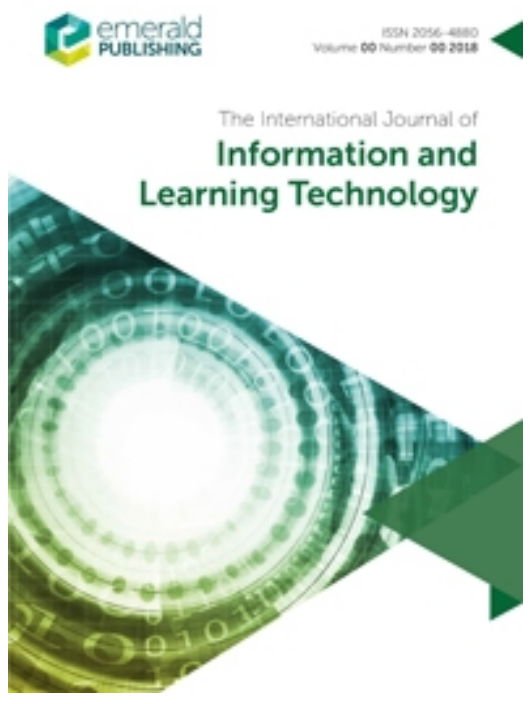

\section{Predictive Learning Analytics and the Creation of Emotionally Adaptive Learning Environments in Higher Education Institutions: A Study of Students' Affect Responses}

\begin{tabular}{|r|l|}
\hline Journal: & International Journal of Information and Learning Technology \\
\hline Manuscript ID & IJILT-05-2020-0077 \\
\hline Manuscript Type: & Research Paper \\
\hline Keywords: & $\begin{array}{l}\text { Predictive Learning Analytics, Emotional Learning Analytics, Affect } \\
\text { responses, Emotions, Student Engagement }\end{array}$ \\
\hline \multicolumn{2}{|l}{} \\
\hline
\end{tabular}

\section{SCHOLARONE Manuscripts}




\title{
Predictive Learning Analytics and the Creation of Emotionally Adaptive Learning Environments in Higher Education Institutions: A Study of Students' Affect Responses
}

\author{
Purpose \\ The aims of this study are to examine affective responses of university students when viewing \\ their own Predictive Learning Analytics (PLA) dashboards, and to analyse how are those \\ responses perceived to affect their self-regulated learning behaviour?
}

\section{Design/methodology/approach}

42 Northern Irish students were shown their own predictive scores on a dashboard. A list of emotions along with definitions were provided which respondents were instructed to verbalise during the experience. Post-hoc walkthrough conversations with participants further clarified their responses. Content analysis methods were used to categorise response patterns.

\section{Findings}

There is a significant variation in ways students respond to the predictions: they were Curious and motivated, Comforted and sceptical, Confused and fearful and with some students being not interested and doubting the accuracy of predictions. We show that not all PLA-triggered affective states motivate students to act in desirable and productive ways.

\section{Research limitations/implications}

This small-scale exploratory study was conducted in one higher education institution with a relatively small sample of students in one discipline. In addition to the many different categories of students included in the study, specific efforts were made to include 'at-risk' students. However, none responded. A larger sample from a multi-disciplinary background that include those who are categorised as 'at-risk' could further enhance our understanding.

\section{Practical implications}

We provide mixed evidence for students' openness to learn from predictive learning analytics scores. The implications of our study are not straightforward, except to proceed with caution, valuing benefits while ensuring that students' emotional wellbeing is protected through a mindful implementation of PLA systems.

\section{Social implications}

Understanding students' affect responses contribute to the quality of student support in higher education institutions. In the current era on online learning and increasing adaptation to living and learning online, our findings allow for the development of appropriate strategies for implementing affect-aware PLA systems.

\section{Originality/value}

The current study is unique in its research context, and its examination of immediate affective states experienced by students who viewed their predicted scores, based on their own dynamic learning data, in their home institution. It brings out the complexities pertinent to implementing student-facing PLA dashboards in higher education institutions.

\section{Keywords}

Predictive Learning Analytics, Emotions, Affect responses, emotional learning analytics. 


\section{Introduction}

Emotions are ever-present in academic contexts. When students attending lectures, undertaking research, completing assignments, taking exams, meeting lecturers, and relating with their peers they experience a wide variety of emotions (Pekrun et al. 2002). In these settings, emotions such as "enjoyment of learning, curiosity, interest, hope, pride, anger, anxiety, shame, confusion, frustration, or boredom are frequent, pervasive, manifold, and often intense" (Pekrun \& Linnenbrink-Garcia, 2014, p.1). D’Mello argues that “on one hand, given the central role of emotions in learning, attempts to analyse (or data mine) learning without considering emotion will be incomplete. On the other hand, giving the ambiguity and complexity of emotional phenomena, attempts to study emotions during learning without the methods of LA [Learning Analytics] and EDM [Educational Data Mining] will only yield shallow insights" (p.116). In this study, we link both the fields by examining students' emotions in an analytics-inspired, learning context.

As teachers and LA researchers, we are interested in designing learning environments that are emotionally adaptive for our students. Therefore, the aim of this study is to help our institution acquire an ability to recognise students' affect responses so that its predictive tools enhance students' emotional experiences of learning. Of course, when institutions are able to predict student performance in a course, it creates new opportunities to target resource utilisation, to tailor instructions and to shape interventions more accurately. It is not surprising then to see a great deal of previous research and institutional investments have focused on making better predictions about students' performance. However, how students emotionally react and respond to viewing their machine-generated predictions has not been fully explored, and such knowledge is important to create affect aware learning contexts. This study addresses this gap. 


\section{Literature Review}

In this section, we review three inter-related streams of literature, namely (a) predictive learning analytics, (b) emotions and (c) emotional learning analytics in academic settings in order to situate our study.

\section{A. Predictive Learning Analytics in academic settings}

Learning analytics (LA) in higher education is an emerging field. It refers to "the measurement, collection, analysis, and reporting of data about learners and their contexts, for purposes of understanding and optimising learning and the environments in which it occurs" (Long and Siemens, 2011). LA uses sophisticated machine-learning data-mining techniques, as well as big data storage and processing capabilities and helps HEIs make decisions and predictions with reasonable accuracy, quickly (Alhadad et al, 2015). Most higher education institutions in the UK and beyond, have begun to understand and appreciate how learning analytics could be used, for example, to provide early interventions that identify and support at-risk students succeed in a course (Sclater, 2014) so that the depleting resources are used on the right students, at the right time, and with the right message (Aguiar et al. 2015).

The vast amount of data collected in the systems can be used both for creating an understanding of a learning-related phenomenon and predicting certain aspects of a phenomenon. Bergner (2016) argues that LA occupies "a methodological middle space between explanatory and predictive approaches" (p. 42). According to Brooks and Thompson (2016), explanatory analytics and predictive analytics, although complementary, are different; while explanatory analytics, as a post-hoc and reflective activity, does not aim to make any claims about the future, but aims to generate an understanding of a phenomenon; predictive analytics however, 
makes claims by making inferences about the uncertain future events. While an explanatory model can be used to make predictions, a predictive model is not necessarily explanatory. In a university, a predictive model can be used to determine when a student is likely to complete their academic degree or whether an instructional style has an impact on students. Then, through custom-designed dashboards, students, as direct consumers of learning analytics, are given opportunities to gain insight into one's own learning behaviour. Dashboards use traffic light symbols to inform students when they are doing well and caution them when they are at risk, with a green or a red signal respectively. Tools such as BlackBoard Predict can assist students at the course level by predicting which students are at-risk of failing a module. Predictive learning analytics is a fast-developing area of research, and several commercial products (e.g., D2L Brightspace Degree Compass, Starfish Retention Solutions, Ellucian, Student Explorer, and Blackboard) now incorporate predictive analytics in the learning content management system. In this study, we are focusing on students' emotional response to viewing a Blackboard Predict generated dashboard.

Empirical research in this area of predictive learning analytics is steadily growing. A recent systematic review of 357 papers published between 2010 and 2018 (Hellas et al. 2018) conclude that within this increasing body of scholarly work, the majority of them looks "at predicting easily attainable metrics such as individual course grade(38\%), individual exam grade $(14.7 \%)$, program retention or dropout $(13.4 \%)$,GPA or cumulative GPA $(12.2 \%)$, and assignment performance (11.4\%)". When predicting students' academic performance, the majority of the articles used academic data for prediction (e.g., predicting course performance based on high-school performance), although use of other features such as "demographic (e.g., age, gender), personality (e.g., self-efficacy, self-regulation), academic (e.g., high-school performance, course performance), behavioural (e.g., log data) and institutional (e.g., high- 
school quality, teaching approach)" are also found. In terms of methodologies used, classification methodologies such as decision trees, and statistical methods such as correlation and regression, are found to be most frequently used to make predictions of academic performance (p. 187).

This emerging area of research and practice is contributing to teaching and learning in several ways. A great deal of previous research into Massive Open Online Courses (MOOCs) has focused on predicting when students might disengage from the learning activity (Chiu et al. 2018; Brooker et al. 2018; Qiu et al. 2016). Various studies have also used predictive models to detect learners who engage in 'gaming the system' in order to answer questions correctly without learning (Baker et al. 2004; 2013). Aguiar et al (2015) describe how predictive models could be used to prioritise students at risk of not graduating high school on time, by understanding the predictors of at-risk students going off track. Baker, Gowda, and Corbett (2011) present a novel method that predicts a student's future performance on a transfer posttest, which involved related but different skills than the skills studied in an Intelligent Tutoring System for College Genetics, using only the first $20 \%$ of a student's data from a tutor lesson. Similarly, Hershkovitz et al. (2013) describe a method to predicting students' preparation for future learning with the use of graphs that display the degree of learning that occurs at specific moments in students' learning trajectories. This study adds to these ongoing predictive conversations, by examining students' affect responses.

\section{B. Emotions in academic settings}

Emotion is a complex phenomenon and there is a lack of agreement in defining what it is. D'Mello (2017) laments that despite the advances we have made in affective sciences, our 
knowledge about emotions is relatively limited. Specifically, we are yet to fully understand the nature of emotions, the conditions under which they occur, and how they impact different learners during learning in academic contexts (Porayska-Pomsta et al. 2013). Despite the lack of a clear definition, a number of authors have contributed to our understanding and knowledge of affective dimensions of learning and we know that emotions can enhance or inhibit learning (e.g. for an overview: Hascher, 2010; Linnenbrink, 2006; Pekrun \& Linnenbrink-Garcia, 2014; Jackson, 2018).

In general, emotions are seen as a dynamic, multi-componential construct that includes physiological, psychological and behavioural aspects. Hascher (2010) invites us to recognise five components of emotion: the subjective experience, of taking an exam for example (affective component), the associated thought processes (cognitive component), the way that experience is displayed as joyful or fearful of exams (expressive component), the impulsive actions that accompany that emotion, reading more or avoiding certain tasks (motivational component) and the way the emotion is demonstrated in one's body, like sweating or increased heart beat (physiological component). Few others view emotions to include moods and feelings too. Since there is no consensus about the use of the term emotion, educational researchers (e.g. Pekrun \& Linnenbrink-Garcia, 2013; Porayska-Pomsta et al. 2013) tend to use a more inclusive term 'affect' to denote a larger category of various non-cognitive constructs including emotion, beliefs, motivation and self-concept. We use the inclusive term 'affect' in this paper.

The study is about labelling the immediate affective states experienced by students in a given learning situation so that we can understand how they respond to viewing a dashboard. To help researchers identify a range of affective states that occur in learning contexts, Pekrun and Stephens (2012) provided us with a taxonomy, known as 'academic emotions' grouped into 
four categories: (a) Achievement emotions (contentment, anxiety, and frustration) are linked to learning activities (homework, taking a test) and outcomes (success, failure); (b) Topic emotions are aligned with the learning content (empathy for a protagonist while reading classic literature); (c) Social emotions (pride, shame, and jealousy) occur because learning happens in social contexts; and (d) epistemic emotions arise from cognitive information processing, such as surprise when novelty is encountered or confusion in the student experiences an impasse. We considered this taxonomy is sufficiently broad and therefore considered as a useful list of affective states that we look for in this study. Having considered briefly the range of affective states a student could experience in a learning context, we now turn our attention to an area that combine these emotions and learning analytics, in the next section.

\section{Emotional learning analytics in academic settings}

There is an increasing recognition that focusing only on the analysis of digital footprints (as in the area of learning analytics) without taking into account of students' emotions can only offer an incomplete view of their learning experience. A number of authors (e.g. D’Mello, 2017, Suero Montero \& Suhonen, 2014; Linnenbrink, 2006; Jackson, 2018), argue for need to integrate emotions and LA studies to better understand learning processes. Lab-based empirical studies that connect in the area of emotional learning analytics have been on the rise. For example, Suero Montero \& Suhonen (2014) highlight the potential of analysing learner's emotions from non-structured text data generated during an online course. They alert LA researchers about the role of negative emotions during learning, and the potential ethical issues with the use of emotion data in LA studies. Vatrapu et al. (2013) contributed to improving LA designs and discourse environments through their eye-tracking study which found higher emotional activation when students using metaphorical traffic lights symbols, similies and 
collective histograms, and evidence of reflective engagement when they use think-aloud comments.

A range of sophisticated knowledge elicitation methods that assist researchers in detecting, labelling and studying affect states in learning have been proposed to help those who are interested in understanding the role of emotions during learning with technology (See reviews: Wosnitza and Volet, 2005; Afzal and Robinson, 2011; Porayska-Pomsta et. al. 2013). With the help of these methods, in the area of affective computing and intelligent systems, for example, affective states have been predictively modelled (D'Mello, et al. 2008) and confident claims have been made. For instance, D’Mello \& Graesser (2012), in their study of students' natural language conversations with an intelligent tutoring system (ITS), they were able to predict the affective states of boredom, confusion, flow, and frustration, experienced by learners during learning. In similar vein, Bosch \& D'Mello, (2017) conducted a lab study on the affective experience of students when they learned the fundamentals of computer programming. They recorded the learning session and asked their students to give affect judgments every 15 seconds over the course of viewing videos of their faces. Their analysis of affect states revealed that engagement, confusion, frustration, boredom, and curiosity were the most frequently experienced, while anxiety, happiness, anger, surprise, disgust, sadness, and fear were rarely experienced by students. They were able to demonstrate how students' interactions with learning tasks give rise to affective states, and how affective states triggered various behaviours. By illustrating how affect is interspersed throughout the learning process, they advanced our understanding of creating affect-aware learning environments. It is in this area of emotional learning analytics, we situate our study that examines students' affect responses to viewing their own predictive learning analytics score in a university setting. 


\section{Institutional context}

Ulster University has approximately 27,000 students distributed across four locations in Northern Ireland and also within the partnership campuses in London and Birmingham, in the UK. It also has approximately 1600 fully online students studying from 48 different countries and all of its courses are offered in blended or fully online modes. As students use online learning systems, as part of normal study activities, their digital footprints are recorded continually in the university systems, along with historical data stored in institutional systems. As a consequence of this continuous, uninterrupted data capture, a richer and a more complete understanding of students' learning behaviour has become possible. The university continues to develop its analytical capabilities for improving learning and teaching by personalising learning contents, student support and feedback, and by monitoring students' online interactions, tools usage and curriculum engagement, so that teachers are empowered to make real-time pedagogical decisions related to course structures, learning design and programme provision. Despite this extensive efforts, students' data have not been shared with them for developing their self-awareness and self-reflection, and there is an increasing desire to learn how to sensitively present meaningful and useful data to everyone, without withholding it from them.

\section{The PLA dashboard in Blackboard Predict}

The university has become the first institution in the European Union to purchase Blackboard Predict, a commercial solution that leverages a predictive model to identify at-risk students. The university has implemented a pilot project on predictive learning analytics in less than a year from its introduction. Through the application of a predictive model, this initiative allowed teachers to make early interventions when a student triggers an early warning system. The 
project sought to enhance intervention strategies with real-time, just-in-time data and to encourage data-informed decision making. The Blackboard Predict system conducts background analysis of both dynamic data produced from a range of instructional technologies (such as LMS data of students' interactions with content, assessments, lecturers, and peers, achievement data from electronic grade books attendance data, library data, etc.), and static historical data (e.g., student demographics, grade point average, residency status, etc.) stored in institutional databases, and provides a visual display, within the LMS workflow (Alhadad et al, 2015). At the university, it uses a percentage score which relates to the likelihood of a student achieving a grade of $50 \%$ or above. It is recognised that this is above the pass threshold for undergraduate modules of $40 \%$; however, historical analysis shows that less than $3.1 \%$ of students scored 40 or below, rising to $14.7 \%$ for $50 \%$ or below. Therefore, the university decided a 50\% grade cut off as more significant as an at-risk indicator for its students. Accordingly, in Ulster University's case, the outcome question being answered for the pilot is, which of the students are likely to pass a course with a 50\% grade or higher? The result of the prediction is a probability that the student will not score greater than $50 \%$. The higher the probability the more likely the student is to fail. This value might be a $75 \%$ probability indicating the student is predicted to fail with a $75 \%$ confidence. What is displayed is the inverse of the prediction (or the probability that the student will succeed). In the example above, the indicator will show $25 \%$, underlining the prediction that it is only a $25 \%$ probability that the student will succeed with a $50 \%$ grade or higher. The system also helps us identify those students, through available engagement indicators, who show similarities with students who have previously dropped out or failed to achieve $50 \%$ or above (see Fig. 1).

Insert Figure 1 here 
As seen in Figure 1, the system identifies the total number of students at risk in a cohort $(\mathrm{n}=152)$, using Red, Amber, and Green status indicators. In this prioritised list of students for tutors to engage with, the student Peter Mullan (a pseudo name) has only a 27\% probability of passing a module and, hence, requires an intervention. Although Predict may appear to facilitate reactionary intervention strategies, staff are encouraged to utilise PLA dashboards as a data source for undertaking proactive support and retention strategies in person. It is believed that lecturers real-time interventions can radically improve the odds that students receive the necessary support they need to be successful before it is too late. As a preparation for making the dashboards available to students, with a view to enable them to better monitor their own behaviours and performance, the institution paused for an interim evaluation, and it offered us an opportunity to understand learners' perceptions on the use and value of LADs. The more we recognise the role of affective states in learning (D’Mello, 2017), the more we were curious to learn how students might respond to seeing data presented in predictive analytics dashboards (Verbert et al. 2013). Students affect responses to viewing this teacher-focused dashboard is the focus of this study.

The following two research questions guided our study:

1. Which emotions do students experience when viewing a machine-generated predictive score of passing a module, in a university setting?

2. How are these emotions perceived to affect students' self-regulated learning behaviour?

\section{Methodology}

In this interpretative qualitative study, we used multi-qualitative methods including individual interviews, paired interviews and focus groups. On obtaining the necessary ethical permission from the university, we recruited and purposively selected $(n=42)$ undergraduates and 
postgraduates, who are studying business innovation and human resources management degrees. The first author taught these students at the time to data collection, which made student access less challenging. A participant information sheet was used to explain the concept of predictive learning analytics to them and they were invited to meet researchers in the offices of Centre for Digital Learning, during their free time, within the university office hours. No academic credits were given to volunteers. To encourage participation a $£ 5$ worth of gift vouchers were given to them. After building rapport with the volunteers, a member of the research team invited them to view their own machine-generated predictive dashboard. This dashboard contained predictions on their likelihood of passing a module, along with other dynamic data on their learning behaviour, captured during the current semester. Considering the potential of a situation in which viewing an undesirable prediction might have a negative impact on a student's well-being, a qualified health practitioner from Student Support was asked to be present in the office during the data collection. We ensured confidentiality, anonymity and students' right to withdraw at any stage, and conformed to data protection protocols. On allowing them to take sufficient time to look at their scores, participants were asked about their immediate affect responses, as per the details explained next. We conducted 16 individual interviews, 3 paired interviews $(n=6)$ with undergraduates and two focus groups $(n=20)$ with postgraduates. The interviewed pairs and the focus group participants were offered an opportunity to view their academic predictions individually. However, the three pairs opted to view the scores together, saying that they normally study together as learning partners and they were comfortable in viewing the predictions as pairs. Among the 20 postgraduates who participated in the focus groups, only one student opted to view her own dashboard. 


\section{Data collection procedures}

We followed guidelines provided by Porayska-Pomsta et al. (2013) in determining our methods. Although instruments for measuring bodily and physiological sensors are available and being seen increasingly as the appropriate tools for detecting human affect states, they were not required for this study. This is because, the predominant purpose of the data being sought in this study was only to understand how the university could prepare itself to support students' learning and wellbeing if and when it decides to open up PLA scores. What was being measured is students' rapid reflective responses to viewing the PLA dashboard and how the temporal granularity of the affective phenomena played a role in the selection of our chosen method. Therefore, we used 'Learners as reporters' - method, using a technique called 'emotealoud' D'Mello et al (2006), following concurrent affect judgement protocols (PorayskaPomsta et al. 2013). In this, participants are asked to report on their affect while engaging in an educational task. Accordingly, in line with the methods used by D'Mello et al (2006), students were asked to report their emotions verbally as they perform a learning task, whereby the task involved in viewing their predictive score on the dashboard. As used in their study, we gave a list of emotions (anger, boredom, confusion, contempt, curious, disgust, eureka, and frustration) along with definitions. They were instructed to verbalise any of these emotions (e.g., "I'm confused" or "I am curious") as they were subjectively experienced when viewing the dashboard. They were also encouraged to express any affective state not included in the list provided, as well as instances in which they experienced multiple emotions. No prompts or probes were used during this emote-aloud session. To strengthen the reliability of our data, we clarified their responses through post-hoc walkthrough conversations with the participants. We recorded and transcribed the participants' concurrent judgements and our post-hoc conversations for offline content analyses. In reporting the data, we have used pseudonyms 
which align to the gender and profile of each student as a way of respecting anonymity while also providing a rich account of their affect responses.

\section{Findings}

Our content analysis helped us to identify three dominant categories of affect responses expressed by participants when they viewed their predictive scores, and a category of students who were not interested in viewing their scores. Their responses had varied influence on their behaviour. Table 1 summarises the meanings of these responses and explain the non-interested category. In the following section, each category is explored in greater depth, using data excerpts that support our interpretations and analysis.

Insert Table 1 here

Only undergraduates (52\%) showed an interest in viewing their predictions and affect responses and perceived behavioural influences were shared only by them. Among the eight emotions listed, 'anger, contempt, disgust, eureka and frustration' were not used by the participants. However, 'curious and confusion' were frequently used by them, along with 'feeling comforted,' fear and scepticism. These affect responses can be grouped as follows.

a. Curious and motivated: Students were eager to view their predictions and they intuitively appraised that the machine-generated predictions will be beneficial and therefore pre-judged the dashboard viewing experience as something good. We could see vividly how they enthusiastically moved towards the monitor and set themselves up ready for an experience. 
It appeared that they believed that something was there worthy of attention. They were excited in anticipation. They were interested and ready to take-in what we were about to show them. Among the emotions listed in the card we gave to them, $28 \%$ of the participants said, phrases such as "I am curious to see it," "Wow! That would be lovely. I am curious!" Immediately after seeing the predictions, they displayed a readiness to act on something, and an intentional preparedness to answer our questions. There was no indication of doubt about the trustworthiness of the prediction, and it was characteristic of this group, as reflected in these extracts:

\author{
"I don't know how it is going to picking up the things. Wow! Let us see!"..... [and after \\ seeing the dashboard]....It is what I expected to see, three ticks to be \\ honest.... Funny enough... I automatically trusted the system. I didn't doubt it for a \\ second" (Mary) \\ “It's kind of weird... I didn't know such predictions existed in Blackboard until today \\ - I wish the university would kind of save this so I could access it. \\ I am curious to see what you are going to show me!" (Harris)
}

When asked about the possible influence of the predictions on their behaviour, these students said that they would be 'motivated to work harder':

\begin{abstract}
“So, now I'm going to...I know now a higher score is achievable, so I'll work towards it. It is motivating.....It would just push me to get to the highest you could get" (Mark)
\end{abstract}

"It would make a change in me to carry on.. and start doing the work before it's too late. It would make me push and work hard to do...to get a good result” (Presley) 
"It is telling me that 'Look, you're in a good place; now, maintain that - keep putting the effort in maintaining that and you will be fine...Yes, it is definitely motivating" (Mary)

These extracts raise powerful insights into how students felt a sense of admiration when viewing the positive predictions. In our system, the dashboard showed a distinct, green coloured score and when viewing the scores, that instantly felt that they were on their way to pass the module with good marks. They felt motivated to invest even more time and energy in performing well in their studies. In the above extract, Mary emphasised the word 'definitely' - highlighted - and the accent indicated a sense of conviction that she would work harder to achieve her best.

b. Comforted and sceptical: A group of students felt 'comforted' when seeing the predictions because the scores confirmed what they already intuitively knew. These students (14\%) felt reassured that their work had been recognised in the system in varying degrees, and they felt consoled. In some cases, they experienced a sense of 'relief' that they are on-course to pass the module. When viewing their predictions, they did not use any of the recommended emotion categories; instead, phrases such as "it is comforting to see the score!" "It is personally comforting!" were frequently used, as seen in the extracts:

"I feel that it's like comforted me a wee bit, knowing that there is a really high chance of passing. I already knew that I would pass the module but seeing it in a kind of black and white makes, it is more comforting" (Myla) 
When asked about the possible influence of the predictions on their behaviour, these students tended to doubt the reliability of the system, and this scepticism is characteristic of this group.

"I don't think blackboard is a good indicator, because all you do is log on to the system to print your slides all at once; and if you're printing your slides, how is that going to say that how many times you read over them or spent time on those slides? I have a printed version in front of me, which most students do, because we take notes on the slides. The predictions based on this type of information is not totally accurate. I will not change what I do now" (Arif)

'I'm good at studying! If the system shows a low score, I will question the system's accuracy!"' (Dionne)

"My family was here last week and I did not use the Blackboard. The computer is not going to know these circumstances. Why should I change the way I act now? (Harris)

Some students express a need for PLA systems to give students more specific predictions about their performance, if dashboards were to be useful:

\footnotetext{
"The university should ask first if a student really want to see their data, and then, the data might be presented more tactfully; if it was done in that kind of like ballpark way. So below $2: 1$, show them the ballpark, and if it is above $2: 1$, be more specific and precise, so that the predictions are seen as useful" (Theo)
} 
Although these students found some value in viewing their predictive scores, one cannot ascertain that there will be a behavioural change in them. Interestingly, these students tended to nurture a sceptical perspective towards the integrity of the system. They have their own reasons for not trusting the scores, in the current format. This finding reveals that not all affective states motivate the students to act. A lack of readiness to act, coupled with suspicion and lack of trust in the system differentiates this group of students from those in the earlier category.

3. Confused and fearful: The third group of students (10\%) were 'confused' when viewing the predicted scores. They did not comprehend fully what they were viewing on the screen. They tended to remain silent when looking at the dashboard. After some delay, they tended to say, phrases such as "I am confused, why this is showing my score in an orange colour?" or "It is confusing".

"I do not fully understand this score. I feel, there should be some support factor for the students - because that can be scary to see the RED, 'Oh, you're going to fail, you're going to fail!', students need some kind of help and support”'(Alex)

“[on seeing a low score] I would've been deflated and then I will be ruminating on that for a good wee while, and then eventually picking myself up and move on.... but there would've been a drop [in motivation] after seeing it- I would've been disappointed obviously but......if I went on and got a 72, would that then make them a little bit more kind of complacent? Not sure! (George) 
When asked about the possible influence of predictions on their behaviour, more-complex emotional experiences came to the fore:

"If my score is in RED, I will feel very very sick. By seeing the comparison scores, I start comparing myself with others and start worrying" (Susanna)

"I think I would occupy myself thinking about classmates who had completed their project already in February, but - I haven't started it! That would be demoralising!" (Theo)

Due to the possible after-effects of viewing their predictions, such as 'feeling sick,' 'demoralising' and 'disappointment,' among others, some students prefer a personalised approach to receiving this information:

\begin{abstract}
"One part of me thinks, the more information I have, the better for me. But then how the university will deliver that information?" ..."If a student finds out that they're on a 55; they're hoping to get a 65 and if they open up their laptop at eleven o'clock at night, that will not be helpful. If in a lecturer's office, if a student can find this out, then the student can say "I knew this would happen because I've had X and Y and so... I want that kind of personalised experience when getting my data" (Isra)
\end{abstract}

The above extracts raise a number of interesting issues in relation to the confusion students might experience when viewing their predictions, and the resulting mental health issues. The finding highlights the importance of a careful implementation of PLA systems in institutions and the simultaneous need to protecting our students' health and wellbeing. 
4. Not interested: A large proportion of participants $(48 \%)$ in this study were not interested in viewing their predictive scores. Almost all of them were postgraduate students. We did not force them to articulate the reasons for not showing an interest, but they kept on spilling reasons such as "I know what will be shown in the dashboard!" "I have no time for this" and "I don't care about that." Interestingly, one of the postgraduates who opted to see her score said in passing:

"Personally, I would like to be in a blissful ignorance- a state in which 'it feels like I'm doing quite well'. I don't want to know if I'm doing badly! (Georgina)

More research is needed to learn more about the blissful ignorance status Georgina is referring to in the above extract. In addition, whether the lack of interest in drawing insights from analytical predictions has some links to their age, maturity, self-efficacy, part-time study patterns, and busy lifestyles also requires systematic investigations. Nevertheless, the range of responses presented here suggests that the participants experience a complex variety of affective responses to PLA judgements and this variation must be carefully considered when implementing PLA systems in HE settings. In the next section, we will discuss the significance and implications of our findings.

\section{Discussion}

By demonstrating four different groups of students' affective responses to learning predictions, our study has given clarity to a widely used yet loosely understood concept of emotional learning analytics. There are three salient points arising from the study: the first is the fresh way of seeing predictive learning analytics from students' perspectives. The second illuminates 
students' perceptions on how affective responses influence their learning behaviour. The third highlights the institutional responsibility to protect emotional wellbeing of students, when implementing PLA.

First, our empirical study adds to the small but growing number of studies on emotional learning analytics, by offering a fresh perspective on students' affective response to viewing machine-generated predictive scores. To our knowledge, there are only few studies, if any, with the exclusive focus on students' affective responses to PLA. Thus, our study contributes to our understanding of what it takes to creating emotionally adaptive learning environments, in HE institutions. Our findings highlight that there may be at least four different groups of students who must be supported and nurtured in business school environments. The 'curious and motivated' students may show higher levels of receptivity to PLA implementations and making them ambassadors of PLA systems could help educate student groups and accelerate system-wide adoption. The 'comforted and sceptical' along with the 'confused and fearful' and 'not-interested' groups might contribute to slow uptake of PLA systems. Recently, Herodotou et al (2020) pointed out factors such as faculty's engagement with PLA system, teachers as "champions", evidence generation and dissemination, digital literacy, and conceptions about teaching online were shown to be important to the scalable PLA implementations. To their list of factors, we add affect-based student groups, identified in this study, as another critical factor for PLA implementations.

Second, this study highlights that students' affective responses do not automatically influence their self-directed learning behaviour positively or negatively. Only the curious and motivated students indicate that they would work harder after viewing the Green score. The second and third groups of students highlight more complex affect responses and they tended to show a 
limited influence of predicted judgements on their behaviours. This reluctance to be inspired by the PLA judgements may be related to the perceived irrelevance of predictions, the possible limitations of the commercial predictive product adopted in institutions or to the potential attitudinal issues related to specific students. Although future research is needed to explore these connections more fully, our study throws light on the complex connections between affect responses and behavioural modifications, institutions must be mindful of, when implementing PLA systems. Furthermore, around half of our participants did not show an interest in viewing their predictive scores, and it is important for institutions to recognise that many students may not necessarily show a readiness to use data-driven insights to improve their learning.

Third, our study identified the possible emotional stress such predictions could cause. Our study identifies and illustrates states such as 'feeling sick,' 'demoralising' and 'disappointing' are experienced by students, when they happened to view scores that are misaligned to their expectations. We take a first step in unearthing the complexities and challenges involved in students viewing their scores, when they were alone or when they have a mental health issue. We argue that institutions should be alert to these sensitivities in students' experience of PLA judgements, in order to help them overcome the possible stress, these systems inadvertently cause. Only then, we will be able to create emotionally adaptive learning envirnoments. Taken together, our study has provided much needed empirical evidence for students' affect responses to predictive judgements and thus, enhanced our understanding of emotional learning analytics, in HE institutions.

Our study has certain limitations. First, this is a small-scale exploratory study conducted in one teaching-focused institution, and with a small sample of students from the business school. A larger sample of students from a multi-disciplinary background could yield a wider range of 
variations in students' affect responses. Second, we made an intentional effort to invite 40 students, identified as 'at-risk' in the system and none of them responded to our call. Integrating their voices in a similar study has the potential to reveal how generalisable our findings are. Additional studies are needed to illuminate further why students identified as 'at-risk' choose not to participate in this kind of studies and when faced with machinegenerated predictive scores, how they might react or respond to such situations. Such studies have the potential to enhance our understanding of how we might create emotionally adaptive environments in HE settings.

\section{Conclusions}

This study focused on students' emotional response to viewing output from Blackboard Predict, VLE generated dashboard. We captured students' experiences in a given learning situation into four categories of response patterns. One of the predominant purposes for the data collection was to understand how the institution could prepare itself to support students' learning and wellbeing based on obtained measures of students' rapid reflective responses to viewing the PLA dashboard. The current study shows that although there may be some value in viewing these scores, it could not be used to ascertain that there will be resulting behavioural change. We conclude that not all affective states motivate students to act. This study highlights the importance of a careful implementation of PLA systems in higher education institutions and the simultaneous need to protect students' health and wellbeing in the process of doing so. In consideration of the use of PLA and the creation of emotionally adaptive learning environments, we have identified different groups who must be nurtured and supported in the learning environments. The 'curious and motivated' students show higher levels of receptivity to PLA implementations, making them potential ambassadors, while the 'comforted and sceptical', the 'confused and fearful' and the 'not-interested' groups of students contribute to 
slow uptake of PLA systems. While we note that further research would be needed in this area to explore the complex connections between students affect responses and behaviour we submit that institutions be aware and take into consideration the sensitivities in the diverse students experience of PLA in order to assist and help them overcome unforeseen possible stress and related effects that could result from use of these systems.

\section{References}

Aguiar, E., Lakkaraju, H., Bhanpuri, N., Miller, D., Yuhas, B., \& Addison, K. L. (2015, March). Who, when, and why: A machine learning approach to prioritizing students at risk of not graduating high school on time. In Proceedings of the Fifth International Conference on Learning Analytics And Knowledge (pp. 93-102).

Alhadad, S., Arnold, K., Baron, J. ...\& Whitmer, J (2015) The Predictive Learning Analytics Revolution: Leveraging Learning, Louisville, CO: ECAR

Baker, R. S., Corbett, A. T., Koedinger, K. R., \& Wagner, A. Z. (2004, April). Off-task behavior in the cognitive tutor classroom: when students" game the system".

In Proceedings of the SIGCHI conference on Human factors in computing systems (pp. 383-390).

Baker, R. S., Corbett, A. T., Roll, I., Koedinger, K. R., Aleven, V., Cocea, M., ... \& Mathews, M. (2013). Modeling and studying gaming the system with educational data mining. In International handbook of metacognition and learning technologies (pp. 97-115). Springer, New York, NY.

Baker, R. S., Gowda, S. M., \& Corbett, A. T. (2011). Towards predicting future transfer of learning. In International Conference on Artificial Intelligence in Education (pp. 2330). Springer, Berlin, Heidelberg.

Bosch, N., \& D'Mello, S. (2017). The affective experience of novice computer programmers. International Journal of Artificial Intelligence in Education, 27(1), 181206.

Brooker, A., Corrin, L., De Barba, P., Lodge, J., \& Kennedy, G. (2018). A tale of two MOOCs: How student motivation and participation predict learning outcomes in different MOOCs. Australasian Journal of Educational Technology, 34(1). 
Chiu, Y. C., Hsu, H. J., Wu, J., \& Yang, D. L. (2018). Predicting Student Performance in MOOCs Using Learning Activity Data. Journal of Information Science \& Engineering, 34(5).

D’Mello, S. K., (2017) Emotional Learning Analytics in Handbook of Learning Analytics. 115-127.

D’Mello, S. K., \& Graesser, A. (2012). Emotions during learning with AutoTutor. In Durlach, P.J \& Lesgold, A.M. (Eds) Adaptive technologies for training and education, Cambridge University Press, 169-187.

D’Mello, S. K., Craig, S. D., Witherspoon, A., Mcdaniel, B., \& Graesser, A. (2008). Automatic detection of learner's affect from conversational cues. User modelling and user-adapted interaction, 18(1-2), 45-80.

Hascher, T. (2010). Learning and Emotion: perspectives for theory and research. European Educational Research Journal, 9(1), 13-28.

Herodotou, C., Rienties, B., Hlosta, M., Boroowa, A., Mangafa, C., \& Zdrahal, Z. (2020). The scalable implementation of predictive learning analytics at a distance learning university: Insights from a longitudinal case study. The Internet and Higher Education, 100725.

Hershkovitz, A., Baker, R., Gowda, S. M., \& Corbett, A. T. (2013, July). Predicting future learning better using quantitative analysis of moment-by-moment learning. In Educational Data Mining 2013.

Jackson, C. (2018). Affective dimensions of learning. In Contemporary Theories of Learning (pp. 139-152). Routledge.

Linnenbrink, E. A. (2006). Emotion research in education: Theoretical and methodological perspectives on the integration of affect, motivation, and cognition. Educational psychology review, 18(4), 307-314.

Pekrun, R., \& Linnenbrink-Garcia, L. (2014). International handbook of emotions in education. Routledge.

Pekrun, R., \& Stephens, E. J. (2011). Academic emotions. In K. Harris, S. Graham, T. Urdan, S. Graham, J. Royer, \& M. Zeidner (Eds.), APA educational psychology handbook, Vol 2: Individual differences and cultural and contextual factors (pp. 3-31). Washington, DC: American Psychological Association.

Pekrun, R., Goetz, T., Titz, W., \& Perry, R. P. (2002). Academic emotions in students' selfregulated learning and achievement: A program of qualitative and quantitative research. Educational Psychologist, 37, 91-106.

Porayska-Pomsta, K., Mavrikis, M., D'Mello, S., Conati, C., \& Baker, R. S. (2013). Knowledge elicitation methods for affect modelling in education. International Journal of Artificial Intelligence in Education, 22(3), 107-140.

Qiu, J., Tang, J., Liu, T. X., Gong, J., Zhang, C., Zhang, Q., \& Xue, Y. (2016, February). Modeling and predicting learning behavior in MOOCs. In Proceedings of the ninth ACM international conference on web search and data mining (pp. 93-102).

Suero Montero, C., \& Suhonen, J. (2014). Emotion analysis meets learning analytics: online learner profiling beyond numerical data. In Proceedings of the 14th Koli calling international conference on computing education research (pp. 165-169).

Vatrapu, R., Reimann, P., Bull, S., \& Johnson, M. (2013). An eye-tracking study of notational, informational, and emotional aspects of learning analytics representations. In Proceedings of the Third International Conference on Learning Analytics and Knowledge (pp. 125-134).

Wang, Y., Heffernan, N. T., \& Heffernan, C. (2015, March). Towards better affect detectors: effect of missing skills, class features and common wrong answers. In Proceedings of the Fifth International Conference on Learning Analytics and Knowledge (pp. 31-35). 
Figure 1: Risk Report sample generated by Blackboard Predict system

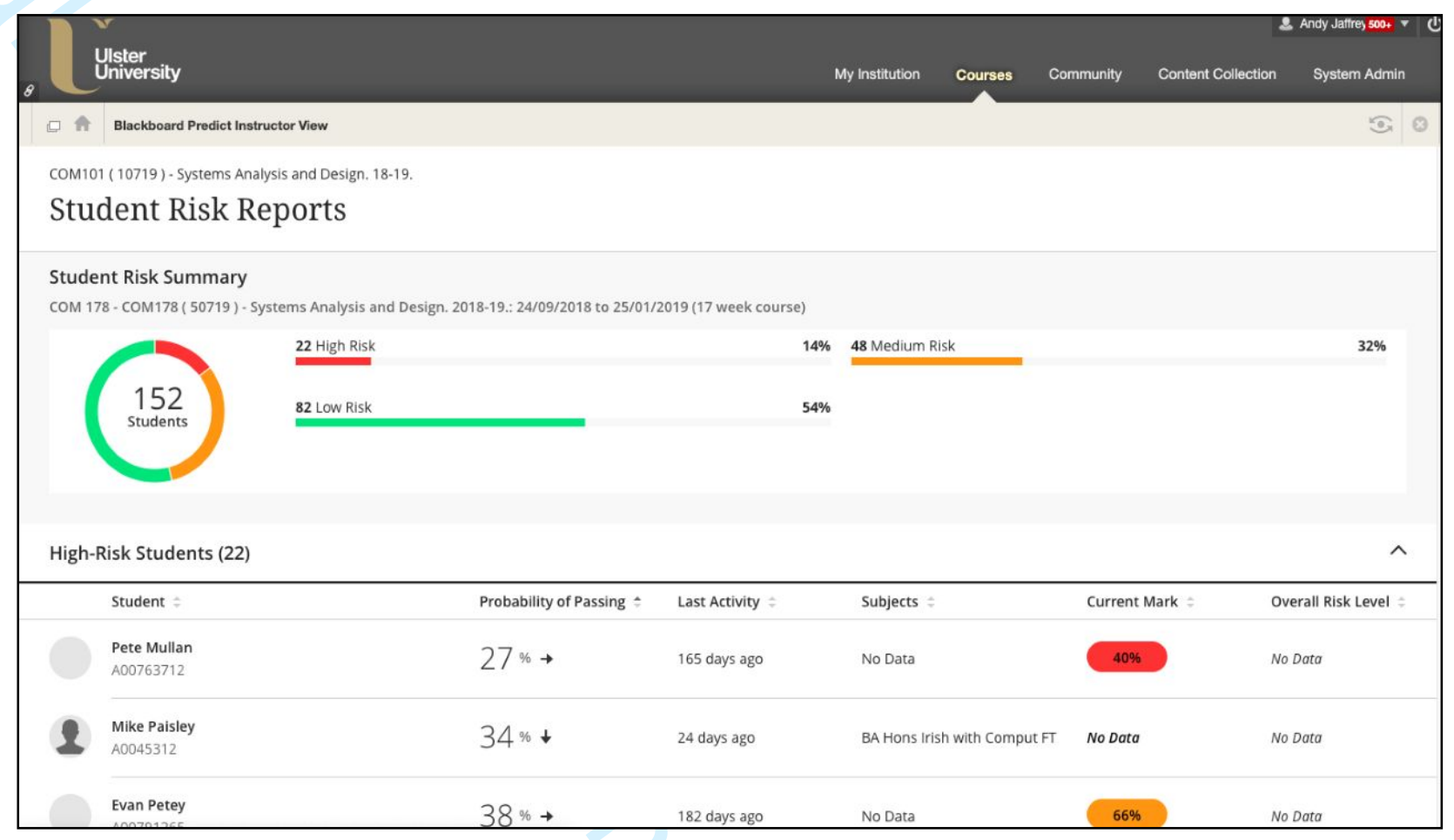


Table 1: Dominant affect responses of students when viewing their predictions

\begin{tabular}{ll}
\hline Affect Responses & Characteristics \& influence on behaviour \\
\hline Curious and motivated (28\%) & $\begin{array}{l}\text { Eager to see predictions and felt re-ignited to make } \\
\text { positive changes, after viewing their scores }\end{array}$ \\
\hline Comforted and sceptical (14\%) & $\begin{array}{l}\text { Lack of any enthusiasm but showed neutral response } \\
\text { to viewing scores; questioned accuracy and } \\
\text { trustworthiness of predictions; concerned about how } \\
\text { predictions should be communicated to students; not } \\
\text { reporting any influence on behaviour. }\end{array}$ \\
\hline Confused and fearful (10\%) & $\begin{array}{l}\text { Confused when viewing their predictions and feared } \\
\text { that an at-risk prediction might demoralise them. }\end{array}$ \\
\hline Not interested (48\%) & $\begin{array}{l}\text { Volunteers, mostly postgraduate students, did not } \\
\text { opt to viewing their scores. }\end{array}$ \\
\hline
\end{tabular}

